\title{
Research on the Reform of Hospital Salary System Based on Problem Orientation
}

\author{
Chenning Yao, Hongwei Xu, Jingyang Yuan, \\ Xiaorong $\mathrm{Fu}$ \\ Children's Hospital Affiliated to Zhengzhou University \\ Zhengzhou, China \\ yaochenning@163.com
}

\author{
Jingwen Sun*, Fei Wang \\ Nursing College of Zhengzhou University \\ Zhengzhou University \\ Zhengzhou, China \\ 1067890674@qq.com
}

\begin{abstract}
The salary system is an important part of human resource management. It is related to the vital interests of employees and is the premise and key to improving work enthusiasm and professional identity. Based on the analysis of the problems existing in the current salary system of the hospital, this paper puts forward some targeted suggestions to provide reference for the reform of hospital salary system.
\end{abstract}

\section{Keywords-Hospital; Salary system; Reform}

Public hospitals are the mainstay of China's public medical service industry and bear important responsibilities for medical services. Under the background of deepening the reform of the medical and health system, the establishment of a salary system in line with the characteristics of public hospitals is an important task of the reform. It is also an important way to break the profit-seeking mechanism of public hospitals and effectively bring into play the public welfare nature of public hospitals. The scientific salary system can effectively exert the enthusiasm of medical staff, enhance the attraction of public hospitals to high-level talents, improve the professional identity of medical staff, help the construction of hospital talents, help improve the level of medical technology, and help the smooth implementation of the reform goal of the medical and health system.

\section{THE CURRENT COMPOSITION OF HOSPITAL SALARIES}

Salary is the monetary income and specific services and benefits that an employee receives as part of an employment relationship[1]. Salary is not limited to economic compensation such as wages, but also includes non-economic compensation such as work environment, social status and development opportunities. The scientific salary system can play a good incentive role for employees and effectively improve work enthusiasm and professional identity.

Public hospitals in China are classified into two types of public welfare units according to public institutions, and differential grants are implemented. At present, the salaries of public hospitals are mainly composed of post salary, scale salary, subsidy and performance salary. Among them, Post salary, salary scale and subsidy are mainly determined by the length of service, professional titles and positions, which are issued in accordance with national standards and relatively fixed. Performance pay is generally directly linked to business income and accounts for a large proportion of wages. In terms of performance salary distribution, most public hospitals implement a secondary distribution system for hospitals and departments, that is, they are first allocated to each department according to the department's income and performance by the hospital, and then the departments are allocated according to factors such as titles and performance. According to the income situation, the income gap between different hospitals and jobs is large. At present, the salary system implemented in public hospitals breaks the one-sided practice of assigning wages in strict accordance with the position and title level, and reflects the distribution concept of "more work, more rewards", avoiding the disadvantages of arranging in order of seniority. To a certain extent, it has stimulated the enthusiasm and initiative of medical staff.

\section{MAIN PROBLEMS AND ANALYSIS}

\section{A. The Overall Income Level of Medical Staff Is Relatively Low, and the Sense of Professional Identity Decreases}

Due to the special nature of medical education, medical staff has the characteristics of long training period and lifelong learning compared with other occupations. According to Wang Yanzhong's survey, the average length of education for medical staff has reached 15.6 years, which is almost twice times of the average level of other industries (about 9 years) [2]. Correspondingly, the income level of medical staff has no obvious advantage compared with other industries. According to the 2017 China Statistical Yearbook, the average income of employees in China's health industry in 2006-2016 is only about $13 \%$ higher than the average income of the society. From the perspective of income growth rate, the income growth rate of employees in the health industry is basically the same as average income of the society. Before 2010, the growth rate of employees in the health industry was even lower than the average income growth of the society (Fig. 1) [3]. From an international perspective, the average income level of medical staff is generally 3-5 times the average social income. According to Liu Ying and other scholars, the income of medical staff in the United States is 3-8 times the average social wage, and the United Kingdom is 2.5-4 times [4]. Compared with the international average level and the average income of domestic industry, the income level of medical staffs in our country is obviously low, which does not match with the professional pay. Coupled with unfavorable factors such as occupational stress and nervous relationship between doctors and patients, resulting in a decrease in professional identity of medical personnel and loss of staff, which has led 
to adverse effects such as the decline in hospital service levels. Especially for high-level talents with strong disciplinary influence and academic level, their salary income and occupational pay have a serious mismatch, which has hindered the development of hospitals and disciplines.

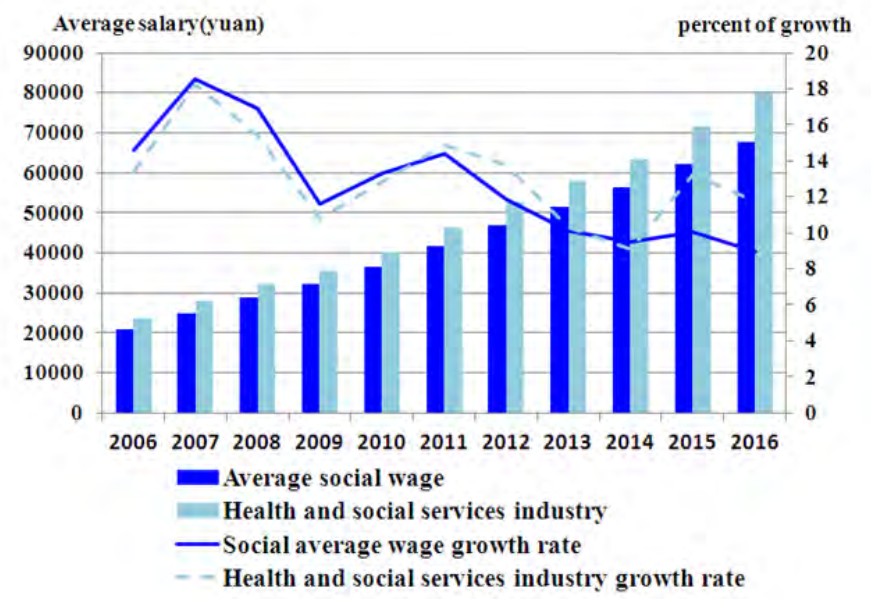

Fig. 1. 2006-2016 social average income situation map.

\section{B. The Internal Income Gap of the Medical Staff Is Relatively Large, and the Work Enthusiasm Is Insufficient}

According to the latest issue of China Health Finance Annual Report, the ratio of hospital employees' performance pay and bonuses to total wages is close to $50 \%{ }^{[5]}$. According to statistics from a hospital in Zhengzhou, the average performance salary of medical staff in the hospital accounted for $77 \%$ of personal income, far exceeding the sum of post salary, salary scale and subsidy. At present, most hospitals have implemented the secondary distribution system of the department, which results in a large gap in the income levels of different hospitals and different departments within the hospital. At the same time, the government's financial support for public hospitals is insufficient. According to a survey of a city-level hospital in Zhengzhou, since 2011, the proportion of government financial allocations to total hospital revenue has dropped from $2 \%$ to $1 \%$, accounting for a very low percentage of total hospital revenue. This shows from the side that the government's financial input has a very limited impact on hospital income, and it is difficult to effectively regulate the income of medical personnel. The income gap between medical staff in different hospitals and jobs is more obvious. According to statistics, the last ten of the total wages of the attending physicians of a hospital in Zhengzhou only account for $30 \%$ of the total wages of the top ten. Therefore, medical staff are more inclined to transfer to higher-income hospitals or departments. However, the number of people in the popular hospitals or departments is very limited. Most of the employees are still in a state of low income, the overall work enthusiasm is affected, which hinders the overall development of the medical and health undertaking.

\section{Non-economic Compensation Fails to Meet the Needs of Employees}

Salary is not limited to traditional wages and other economic compensation, but also includes the professional environment, development of training, vacation and other noneconomic compensation. According to Maslow's hierarchy of needs, after low-level needs such as physiology and safety are met, high-level demands for respect and self-realization will continue to grow, and these are closely related to the creation of working atmosphere and career development opportunities in non-economic compensation. In particular, hospital work has the characteristics of high intensity, high risk, and rapid knowledge update. Medical staffs generally have large work pressures, and there is an urgent need for other aspects of care other than economic compensation. Therefore, the scientific non-economic compensation system plays an important role in doctors' job satisfaction, medical service quality and sustainable development, and in some cases can even produce stronger incentives than economic compensation. However, at present, in Chinese hospitals, there is a high degree of concern about economic remuneration. In the non-economic remuneration such as professional title evaluation and development training, there is insufficient attention. The frontline personnel lack the corresponding right to speak, and the actual needs of medical personnel cannot be met, which reduce the enthusiasm and satisfaction of work.

\section{REFORM PROPOSALS FOR HOSPITAL SALARY SYSTEM}

\section{A. Reasonably Improve the Income Level of Medical Staff and Enhance Professional Identity}

The hospital has the basic attributes of public welfare and service. It should reasonably improve the income level of medical staff under the premise of China's national conditions to enhance their professional identity and reduce the loss of high-level medical staff. According to a survey by Li Fen et al., in Shanghai, where the level of medical development is relatively high, the average wage of hospital employees is $2-3$ times the average social wage [6]. This number has a strong reference significance for improving the income level of medical staff. In practice, for hospitals with higher incomes, the government should liberalize the proportion of salary expenditures in total hospital expenditures, support hospitals to explore the agreement wage system and annual salary system, establish a salary dynamic adjustment system, realize the linkage between employee income and hospital benefits, and stimulate the enthusiasm and professional identity of medical staff. The total salary expenditure of the hospital can be moderately increased on the basis of the previous year's wage level, and can be checked annually with reference to (1).

$$
\mathrm{P}_{\mathrm{N}}=\mathrm{P}_{\mathrm{L}} \times(1+\alpha) \times \frac{\beta}{80}
$$

Among them, $\mathrm{P}_{\mathrm{N}}$ is the total salary expenditure of the hospital in the current year, $\mathrm{P}_{\mathrm{L}}$ is the total salary expenditure of the hospital in the previous year, $\alpha$ is the average growth rate of local wages, and $\beta$ is the hospital evaluation coefficient. This parameter can be assessed according to the characteristics of local development, the ratio of the comprehensive bed staff, the proportion of medical income (including registration fees, nursing expenses and other labor costs), the total medical insurance control situation and the situation of patient complaints. The score is that 60 points pass, 80 points up to standard, and out of 100 points. According to the (1), the 
hospital can guarantee the medical staff salary growth rate to reach the local average level in the case of up to standard; if the score is full, the income level can be increased by $25 \%$; if the assessment is passing, the salary will be greatly reduced this year. Equation (1) can effectively curb hospital large inspections, large prescriptions and other issues, guide the hospital to strengthen the connotation construction, enhance the enthusiasm of medical staff, and improve the level of medical services.

For grassroots medical and health institutions, the government can carry out hierarchical classification management, and set up different assessment systems and assessment targets for medical institutions which undertake different medical tasks and in different levels. According to the assessment situation, the salary of relevant medical institutions will be honored to make it close to or reach the average level of local medical staff's income, enhance the attraction of grassroots hospitals to talents, and improve the stability of grassroots medical staff. At the same time, the government needs to increase investment, pay attention to the follow-up training of medical staff in primary medical institutions, improve their medical level and service capacity, enhance the trust of patients, and gradually improve the income status of primary medical institutions.

\section{B. Optimize the Salary Distribution System and Stimulate Work Enthusiasm}

For the problem of relatively serious income imbalance within the hospital, it must be analyzed in the overall situation of the hospital's overall work. First of all, it is necessary to clearly adhere to the concept of "more work, more rewards". According to the risks, responsibilities and service quality of different positions, we will establish a "post-centered" salary payment system to achieve equal pay for equal work and break the impact of compilation in salary distribution. Secondly, it is necessary to take into account the differences in different positions such as medicine, nursing, medicine and technology among different positions. Drawing on the reform measures of Sanming City in Fujian Province, within the total salary approved by the hospital, the doctor (medical technology) team, the nurse team and the administrative logistics team can be allocated independently according to the proportion of $50 \%, 40 \%$ and $10 \%$. At the same time, salary distribution also needs comprehensive title, workload, service quality, length of service, work risk and intensity to determine the salary distribution system, and tilt to the clinical front line with high technical risk and high work intensity, fully embody the value of core elements such as knowledge, ability and technology, and stimulate the enthusiasm of medical staff to work. Thirdly, we should change the tendency of "focusing on scientific research and ignoring clinical, paying attention to papers and ignoring services", increasing the effect weight of medical service quality and patient evaluation on pay, guiding medical staff to strengthen the emphasis on clinical work, and improving the quality and level of medical services. At the same time, the hospital also needs to establish an effective salary adjustment mechanism based on the secondary allocation of the department. For "unpopular departments" with limited income from some businesses such as pediatrics, hospitals should increase their support, take care of these departments in the salary distribution, increase the income level of relevant personnel, reduce the flow of people due to income problems, ensure the business capability and service level of the "unpopular departments", and reflect the public welfare characteristics of public hospitals.

\section{Adhere to the "People-oriented" Concept and Strengthen the Role of Non-economic Compensation}

In the final analysis, the reform of the salary system is to stimulate the enthusiasm and sense of identity of employees, and it is necessary to motivate the actual needs of employees. And the hospital is an academic and knowledge-intensive unit. Medical staffs pay more attention to the innovative spirit of individualization and autonomy, and pay more attention to the development of career and self-value. Therefore, public hospitals must adhere to the "people-oriented" concept in the reform to avoid the situation that managers work behind closed doors. In terms of non-economic salary incentives, as for the titles and professional development issues closely related to the interests of employees, the hospital should select the senior title winner such as chief physicians and nurses from the front line to form professional academic and professional development institutions to make and review relevant system programs, supervise the implementation of relevant programs, and effectively establish a long-term mechanism that can promote employee growth and overall development. At the same time, the hospital should respect the individuality and rights of employees, establish fair, smooth and effective feedback channels, stimulate employees' sense of responsibility and initiative, and achieve a "win-win" between employees and hospitals.

\section{Innovate High-level Talent Incentive System to Improve Development Level}

Talents are an important resource for hospital development. As the core of the hospital's talent team, high-level talents are the leaders of academic and academic development, and the key to determining the direction and level of competition of hospitals. Therefore, in the process of reforming the salary system of public hospitals, it is necessary to establish a targeted salary incentive system for high-level talents and improve the development level of hospitals. First of all, in terms of economic remuneration, in addition to continuing to give high-level talents scientific research start-up funds, home-based expenses and other one-off incentives, it is also necessary to establish an effective assessment system and long-term incentive mechanism for high-level talents. In terms of the assessment system, it is necessary to establish a comprehensive evaluation system based on factors such as academic achievements, team building, project declaration and work quality, and set corresponding incentive policies for different indicators and projects to ensure that different incentives are given according to the size of contributions on the basis of fair, just and scientific evaluation. At the same time, the economic salary of high-level talents should not be included in the total approved wages of the hospital. While encouraging hospitals to actively introduce high-level talents, it should avoid the phenomenon of excessive differentiation of hospital internal income levels. On the one hand, the establishment of a high-level talent incentive system can focus on high-level talents, gradually form a high-level medical 
research team, and improve the overall level of the hospital. On the other hand, it can solve the shortcomings of the current sustainability of salary incentives in a task-oriented manner, reflecting the high-level talent human capital value and technical value.

The scientific salary system can effectively stimulate the enthusiasm and professional identity of employees, improve the quality and efficiency of work, and promote the efficient development of various hospital work. Therefore, in the new round of medical and health system reform, through the effective reform of the salary system, improve the economic salary distribution system, establish and improve the noneconomic salary incentive system, attract first-class talents, enhance the service capacity of public hospitals, and promote the hospital's human resources work into a virtuous cycle.

\section{REFERENCES}

[1] G.T. Mirkovich and J.M. New, Chengde Translation. Salary Management: 9th Edition, Beijing: Renmin University of China Press, 2008 .

[2] Y.Z. Wang and W.Z. Gao, "Thoughts and Suggestions on the Reform of Salary System for Medical Staff in Public Hospitals," Chinese Health Talents, vol. 4, pp.18-21, 2014.

[3] National Bureau of Statistics of the People's Republic of China. China Statistical Yearbook-2017. Beijing: China Statistics Press

[4] Y. Liu, L.B. Liang, H. Sun, Q.H. Wu, Z. Kang, and Y. Cui, "International Experience of Salary Incentives in Public Hospitals and Its Enlightenment to China," Chinese Hospital Management, vol. 35(6), pp. 12-15, 2015.

[5] Health and Family Planning Commission of the People's Republic of China. 2013 China Health Statistics Yearbook. [EB/OL]. (2014-08-25). http://www.nhfpc.gov.cn/htmlfiles/zwgkzt/ptjnj/ Year/2013/index2013.html

[6] W. Xia and L.K. Yan, "Research on the salary system of doctors in public hospitals in China.," Chinese Hospital, vol. 20(4), pp. 40-43, 2016. 